difference. Multiple analysis showed that hot flushes were associated with being in peri or postmenopause $(\mathrm{RP}=2.12,95 \% \mathrm{IC}=1.52$ $-2.94, p<0.001)$. The complaint of vaginal dryness was inversely associated with marital status $(\mathrm{RP}=0.67,95 \% \mathrm{CI}=0.49-0.90$, $\mathrm{p}=0.007)$, and directly associated with age $(\mathrm{RP}=1.03,95 \% \mathrm{IC}=1.01$ $-1.06, p=0.017)$ and being in peri-and postmenopause $(R P=1.69$, $95 \% \mathrm{IC}=1.10-2.60, \mathrm{p}=0.016)$. Depression was inversely associated with performing work $(\mathrm{RP}=0.74, \mathrm{CI}=95 \% 0.58-0.96, \mathrm{p}=0.022)$ and directly associated with the presence of chronic diseases $(\mathrm{RP}=1.30$, IC 95\% $=1.01-1.067, \mathrm{p}=0.043)$. Insomnia was associated to IMC (RP $=0.96$, CI 95\% $=0.95-0.97, \mathrm{p}<0.001)$ and peri-or postmenopausal ( $R P=1.48,95 \%$ CI $1.11-1.97, p=0.008)$. The serological status in relation to HIV has not been associated with any climacteric symptoms evaluated.

Conclusions HIV infection in these groups was not associated with vasomotor symptoms, genito-urinary, psychological, and insomnia.

\section{P2.184 FOLLOWING OF NEWLY MANAGED ADULT HIV INFECTED PATIENTS IN THE NATIONAL REFERRAL CENTRE, BURKINA FASO: THREE YEARS OUTCOMES STUDY}

\author{
doi:10.1136/sextrans-2013-051184.0448
}

'Y Sagna, ${ }^{1} \mathrm{H}$ Tiéno, ${ }^{1} \mathrm{O}$ Guira, 'I Diallo, ${ }^{1} \mathrm{E}$ A Diendéré, ${ }^{1,2} \mathrm{~J}$ Y Drabo. 'Internal Medicine department, Yalgado Ouédraogo University Hospital (CHU YO), Ouagadougou, Burkina Faso; ${ }^{2}$ African network of training on HIV (RAF-VIH), Ouagadougou, Burkina Faso

Background 10 years ago in Sub-Saharan countries, lab tests and antiretroviral therapy (ART) were expensive for most of patients. Many patients weren't able to start ART and those who start were frequently lost to follow-up. Since few years in Burkina-Faso, testing and treatment facilities are more available, ART is subsidised and starting when CD4 $<350$ cells $/ \mu$ l. We aimed to describe the present follow-up features among newly managed adult HIVinfected patients in this country national referral centre.

Methods a prospective and descriptive review was conducted, using a personal case report forms, in all newly managed adults with positive HIV antibody received between June and December 2009 at Yalgado Ouédraogo Hospital University Internal Medicine department in Ouagadougou. Each treated patient was followed-up for 36 months and had an appointment each 3 month the first year and each 6 month after with CD4 count and viral load measurement. All lab tests and ART were free of fees.

Results We received 191 patients with a median age of 37 (range, 18-65) years, sex ratio (M/W): 0.66. 177 patients returned to medical follow-up after the first consultation. 144/177 patients had CD4 $<350$ cells $/ \mu \mathrm{l}$ and have all been treated (first line). 128/144 treated patients were followed-up for the full 36 months and we have not recorded any major side effects of ART but the incidence of diabetes and dyslipidemia was respectively $2.3 \%$ and $1.6 \%$. 10 died and 7 were lost to follow up. The global compliance rate with appointments was $90 \%$. Weight gain and immune restoration were significant $(p<0.01)$. Two patients had a virological failure during the second year and they successfully switched to the second line treatment.

Conclusion we have excellent treatment success with no major side effects but we still lost to the follow-up some patients and mortality remains high.

\section{P2.185 HPV AND PREGNANCY: THE CONTROVERSIAL ROLE OF MATERNAL-FETAL TRANSMISSION}

doi:10.1136/sextrans-2013-051184.0449

${ }^{1}$ M Skerlev, ${ }^{2} \mathrm{M}$ Sirotković-Skerlev, 'S Ljubojević. 'Department of Dermatology and Venereology, Zagreb University Hospital and Zagreb University School of Medicine, Zagreb, Croatia; '2Department of Pathophysiology, Zagreb University School of Medicine, Zagreb, Croatia
Background and open questions Human papillomavirus (HPV) associated pathology represents one of the major problems among STIs mostly due to the high recurrence rate, difficult eradication and oncogenic potential. Young, sexually active population in the generative period is mostly affected. Pregnancy may definitely foster the development of latent or manifest HPV infections and may enhance the development of the pathology which then often recedes in the postpartum. The data reported in the literature on the relationship between HPV and pregnancy are highly controversial. A number of different opinions emerge regarding the possibility of maternal-fetal virus transmission. This discrepancy depends on the diagnostic techniques, the clinical history and the period of pregnancy when the sample is collected. The possible maternal-fetal transmission of the virus might be considered, for example, the main factor responsible for juvenile laryngeal papillomatosis, and the onset of the genital warts in children's age (apparently more often than the child's sexual abuse which should not be neglected either!). Many authors report an initial presence of HPV in newborns which often disappears within 6 months after birth.

Conclusion According to the most recent vaccination recommendations, HPV vaccines are not recommended for use in pregnant women. However, pregnancy testing is not needed before vaccination. If a woman is found to be pregnant after initiating the vaccination series, no intervention is needed; the remainder of the 3-dose series should be delayed until completion of pregnancy. Providing the controversies that still exist, modes of HPV transmission in pregnancy should be investigated more detailfully in order to get clearer picture and a fuller awareness of the preventive measures. It can be concluded that, in this very moment, there is a need for a coordinated effort of health professionals and policymakers to ensure successful implementation of vaccination programmes for both women and men.

\section{P2.186 MANAGEMENT OF GENITAL HPV INFECTION IN MEN}

doi:10.1136/sextrans-2013-051184.0450

${ }^{1} \mathrm{~F}$ Sandru, ${ }^{2} \mathrm{~A}$ V Dragodan, ${ }^{1} \mathrm{M}$ C Dumitrascu, ${ }^{3} \mathrm{G}$ Turcu, ${ }^{3}$ D Forsea..$~ "$ Euromed" Medical Center, Bucharest, Romania; " $"$ Stefan S Nicolau" Institute of Virology, Bucharest, Romania; ${ }^{3 " C a r o l}$ Davila" University of Medicine and Pharmacy, Bucharest, Romania

Background HPVgenital infections is not yet a STD to be reported. The actual incidence and prevalence are increasing and should be updated using new molecular biology techniques. In men it is more difficult to establish prevalence because of difficult sampling of a suitable biological product.

Methods The study involved the participation of 105 men (20062011), aged 18-55 years, selected from patients with external anogenital lesions with HPV suspected aetiology or who had partner/ sexual partners with clinical lesions and/or positive test for HPV. The tests used for HPV DNA detection and genotyping were: HPV INNO - Lipa HPV genotyping Line Probe Assay EC (Innogenetics) and LINEAR ARRAY HPV genotyping test (Roche Diagnostics).

Results HPV distribution and the genotypes most commonly found were: in men without clinical signs - 26 cases $(24.76 \%) / \mathrm{HPV}$ $18,45,6,11,16,31,33,61,66, \mathrm{CP} 6108$, and those with acuminate and external genital flat warts -16 cases $(15.23 \%) / \mathrm{HPV} 6,11, \mathrm{X}$ (indeterminate), 40, 45, 55 - single or multiple infection.

The applied treatment was: Inosinum PO for porting cases, Inosinum $\mathrm{PO}$ and $\mathrm{CO}_{2}$ laser vaporisation for those with external anogenital warts acuminata 13 cases $(12.38 \%$ ), or Inosinum PO and local podophyllotoxin $0.5 \%$ for those with external genital warts flat 3 cases (2.85\%).

Conclusion Proper counselling of symptomatic or asymptomatic male patients infected with HPV, together with using all investigative protocols and personalised therapy, provides, in $90 \%$ of cases, healing of external genital lesions induced by HPV virus and negative results for HPV tests. 